Faculty, Energy, Environment \& Resource Sustainability

\title{
Organic Pollutants Along The Qatari Coast: A Case Study of The Pearl Oyster (Pinctada radiata)
}

${ }_{1,2}^{2}$ Noora AlJathelah AlShamary, ${ }^{2}$ Debapriya Mondal, ${ }^{2}$ Simon Hutchinson

Qatar University, Environmental Science Center, P.O. Box 2713, Doha, Qatar

${ }^{2}$ University of Salford Manchester, School of Environment \& Life Studies, Salford, M5 4WT, United Kingdom

\section{Abstract}

The Qatari marine environment is endangered due to high industrial expansion and anthropogenic pressure over the last few decades. The presence of common contaminants such as Total Petroleum Hydrocarbons (TPHs) and Polycyclic Aromatic Hydrocarbons (PAHs) is a threat to the marine environment. The aim of this study is to determine the environmental threats and risks posed by organic contaminants to Qatar's marine environment using pearl oyster 'Pinctada Radiata' as the indicator study organism. The samples (marine sediment, seawater, and oysters) were collected four times within two years in different seasons from the four sites (Simaisma Al Khor, Umm Bab, and Al Wakra), March 2017, December 2017 May 2018, and November 2018. A total of 144 samples were analyzed, 48 samples of seawater, 48 samples of sediment and 48 samples of oysters. Levels of organic contaminants (TPHs and PAHs) were quantified in seawater, marine sediment and oyster tissues (P. radiata). In addition, the TOC and particle sizes were measured in abiotic matrices as well as the temperature, salinity, and $\mathrm{pH}$ of seawater in the study areas. Overall, the organic contaminants (TPHs and PAHs) were more readily detected in oyster tissue samples than marine sediment and seawater samples collected from the same areas. The surface seawater samples showed negligible levels of PAHs, while TPHs were ranged from 1.164 to $271.77 \mu \mathrm{g} / \mathrm{L}$. The concentration of TPHs and PAHs in surface marine sediment were ranged between $(75.02-1751.82)$ and $(4.25-36.73) \mu \mathrm{g} / \mathrm{kg}$ dry weight respectively. In oyster tissue samples, the level of TPHs was ranged from 633.33 to $6666.67 \mu \mathrm{g} / \mathrm{kg}$ dry weight, with the highes concentrations measured in Simaisma, while PAHs concentration showed an extreme variation from 25.90 to $2244.03 \mu \mathrm{g} / \mathrm{kg}$ dry weight. The present study could, however, provide useful background information for further investigations to understand the presence of organic contaminants in Qatar's marine environment.

\section{Aim \& Objectives}

The aim of this study is to determine the environmental threats and risks posed by organic contaminants to Qatar's marine environment using pearl oyster 'Pinctada Radiata' as the indicator study organism. The specific objectives are to quantify the levels of organic contaminants (TPHs and PAHs) in abiotic matrices (seawater and sediments) and biotic tissues of P. radiata from different locations in Qatar and to explore the relationships of the levels of these contaminants between the biotic and abiotic matrices.

\section{Sampling and Study Area}

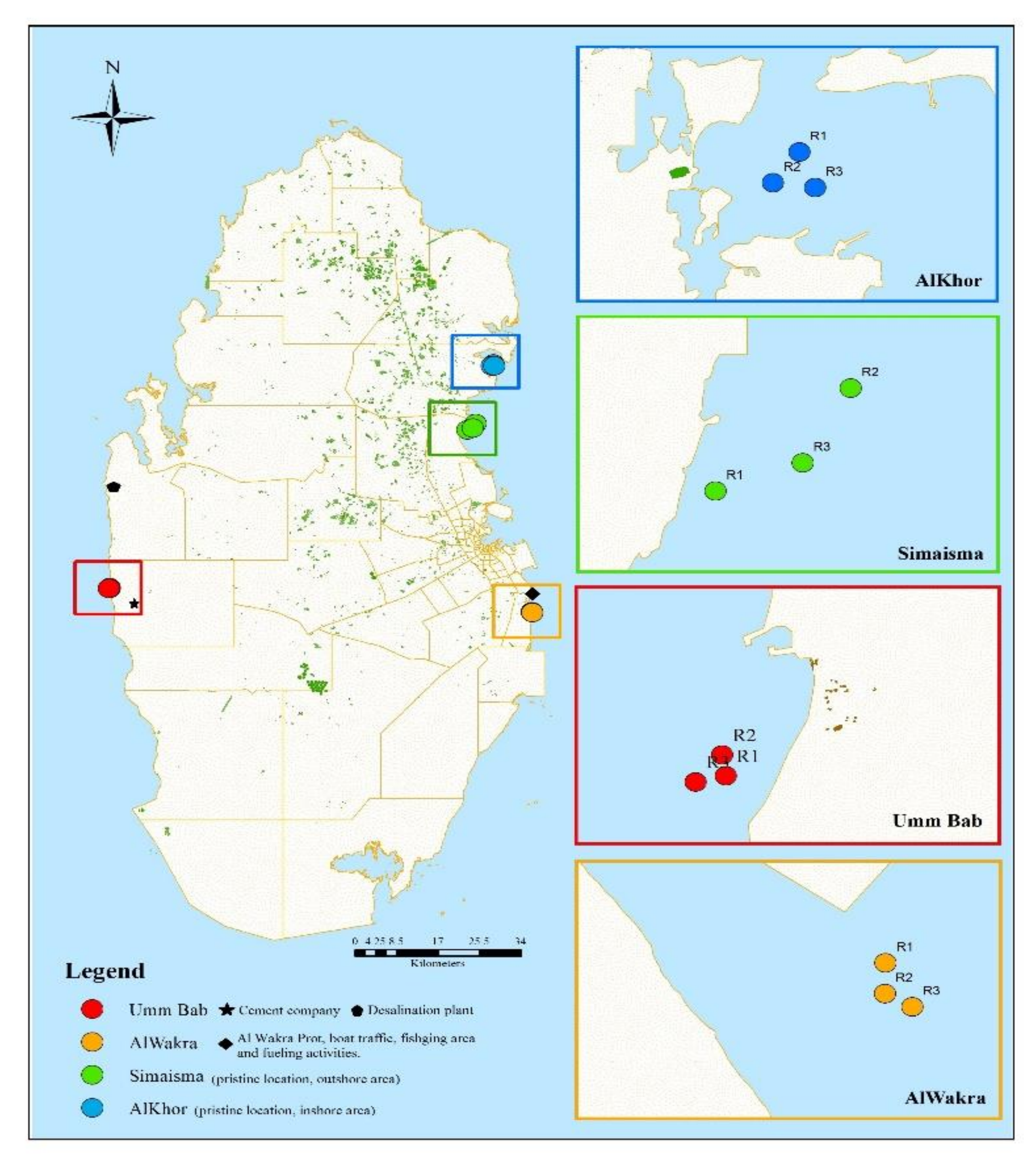

Figurel: Locations of the sampling sites in Qatar coastal zone

- Sampling procedure:

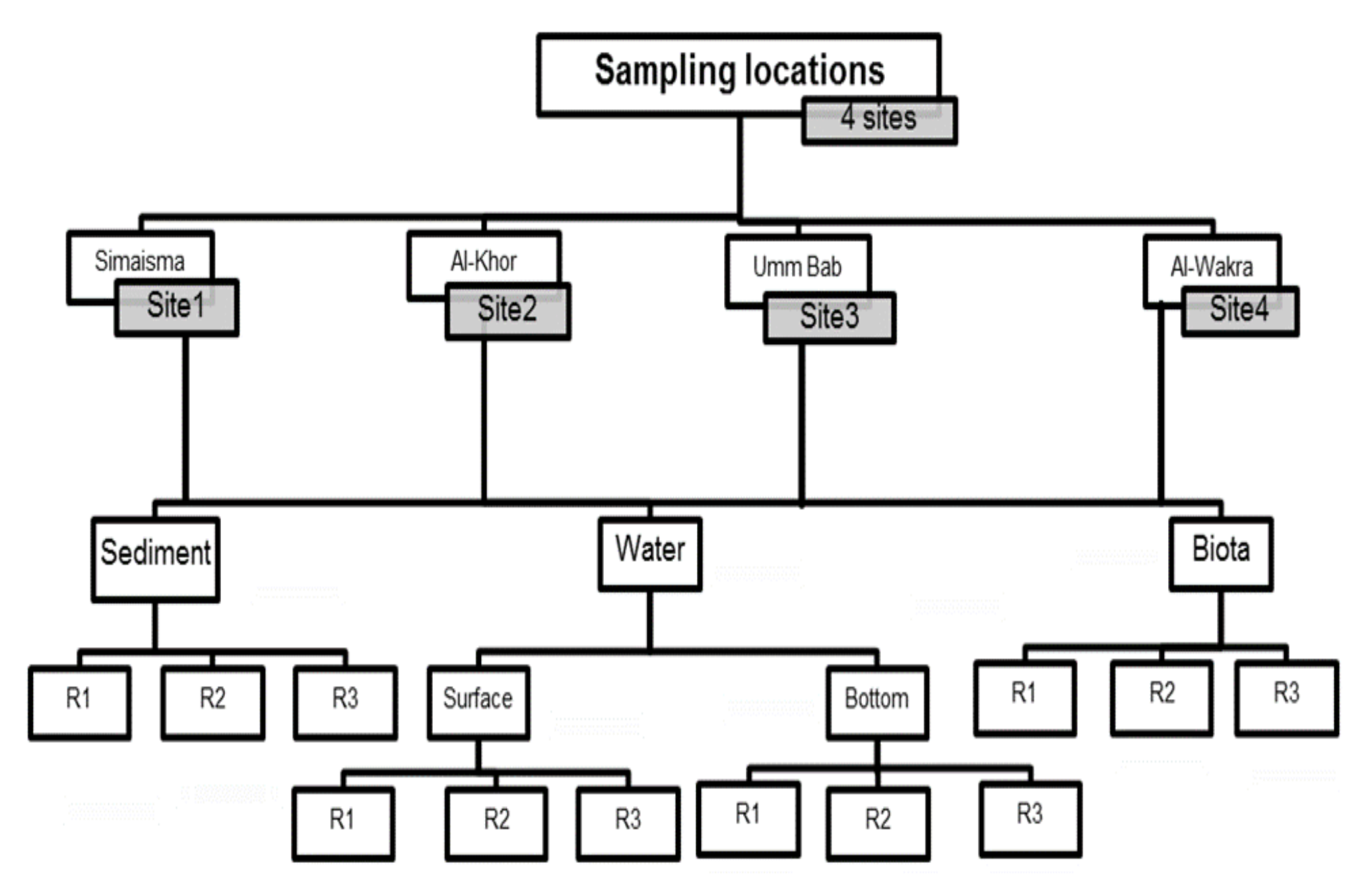

\section{Samples Preparation and Extraction}

- Preparation of sediment and oyster tissues samples
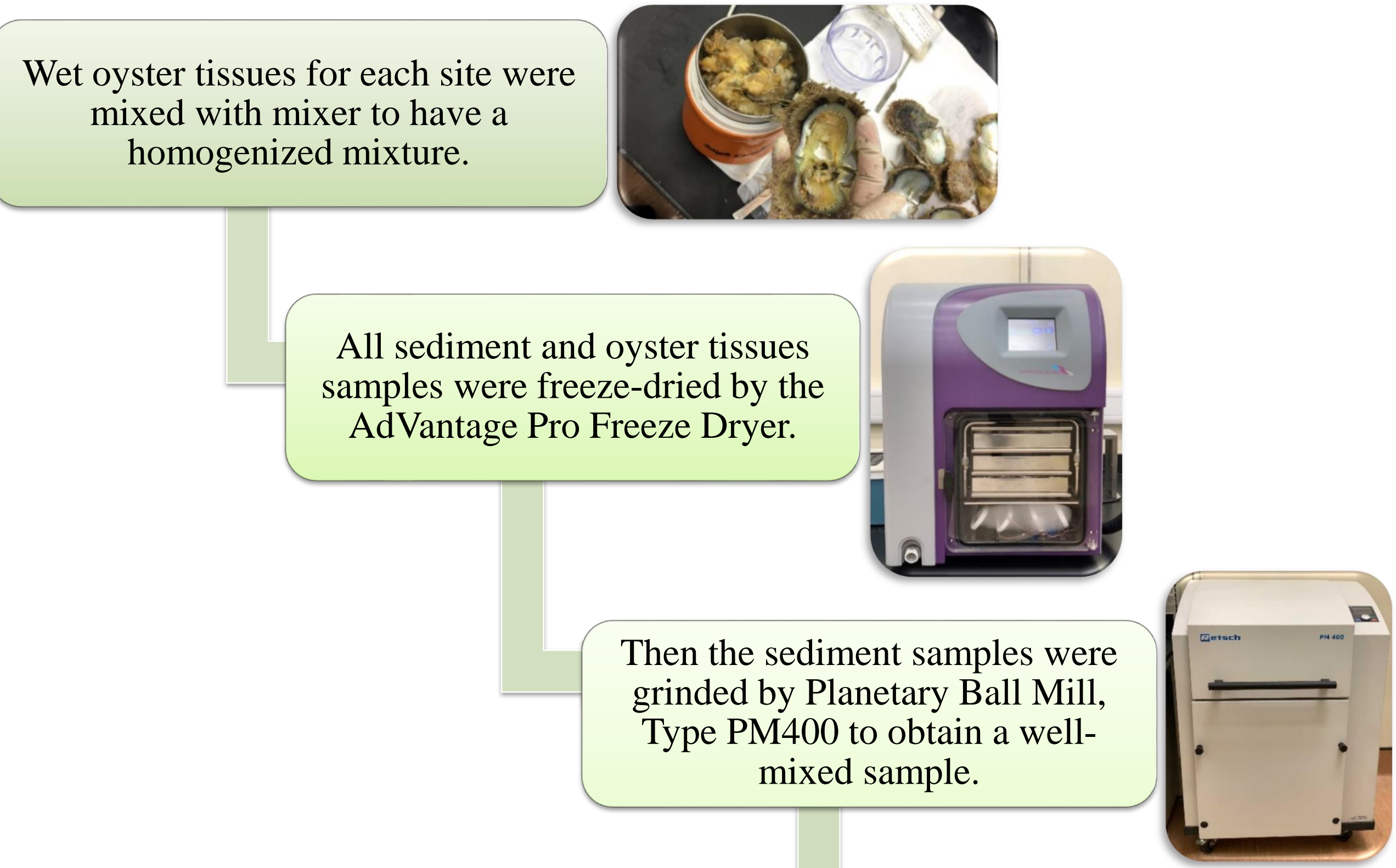

Both the grinded sediment and oyster tissues samples were placed

- Sediment and Oyster tissues Extraction for GC Analysis

Ten grams of sediment sample (or $1 \mathrm{~g}$ of biota sample)
was mixed with $5 \mathrm{~g}$ diatomaceous earth and placed in an extraction cell that contains $20 \mathrm{~g}$ alumina.

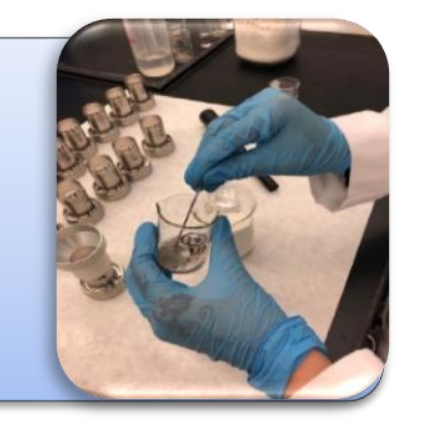

Dionex 350 Accelerated Solvent Extractor (ASE) (USperformed by using was used. The extraction was mixture a a tencriature of $105^{\circ} \mathrm{C}$ and a pressure of
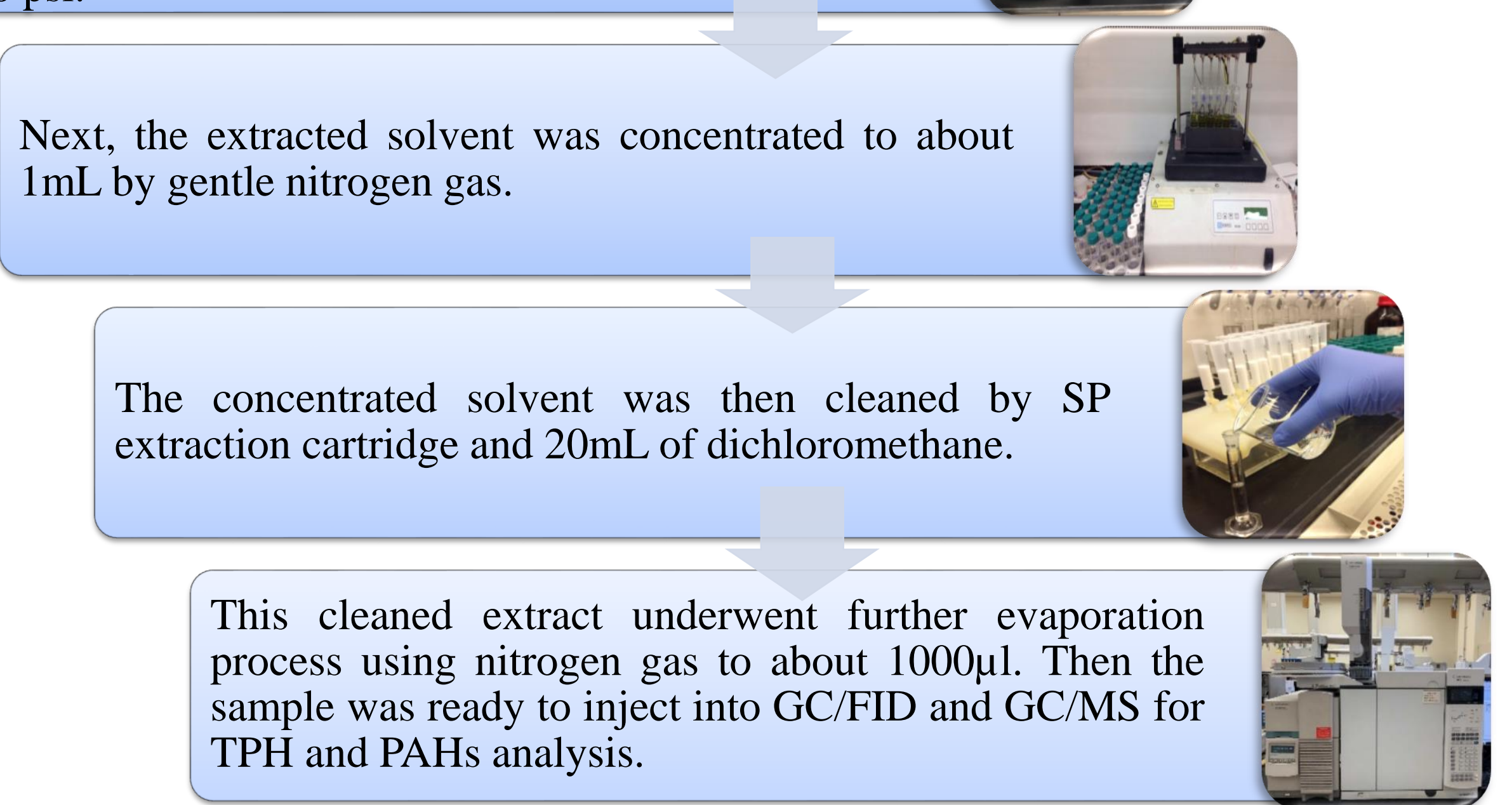

- Seawater Extraction for GC Analysis

EPA (3510C) extraction process of organic pollutants from water samples by the liquid to liquid extraction was followed. Briefly, 1L of water sample was separated in separating funnel by adding $30 \mathrm{~mL}$ of hexane and shaking for 2 minutes resulting in the formation of wo layers. Then, the organic layer was taken off and cleaned by artridge before concentrating it to $1 \mathrm{~mL}$ using nitrogen gas.

\section{Samples Analysis}

- Analysis of TOC

TOC content in marine sediment samples was measured indirectly by analyzing total carbon (TC) and total inorganic carbon (TIC) using (PrimacsSNC100 - SKALAR instrument). Peak area results for TC and TIC obtained from the instrument were used in the standard calibration curve equation to calculate $\%$ TC and \% TIC in sediment. The \% TOC was determined by the following formula: $\%$ TOC $=\%$ TC $-\%$ TIC.

- Analysis of particle size

About 2 to $5 \mathrm{~g}$ (depending on the sediment texture) of fresh wet marine sediment samples were sieved through $2 \mathrm{~mm}$ mesh size sieve and analyzed for size distribution by Mastersizer 3000, Malvern analyzer.

\section{- Analysis of TPHs and PAHs}

The TPHs was analyzed using an Agilent 6890N Network Gas Chromatograph (GC) with Flame Ionization Detector (FID), and for the PAHs analysis Agilent 7890B gas chromatograph coupled to a 5975C tripleaxis mass spectrometer (GCMS) was used. Table 12 and 13 show the conditions of the GC used for the analysis.

$$
\text { Table 1: GC/FID conditions used for analysis of TPHs }
$$

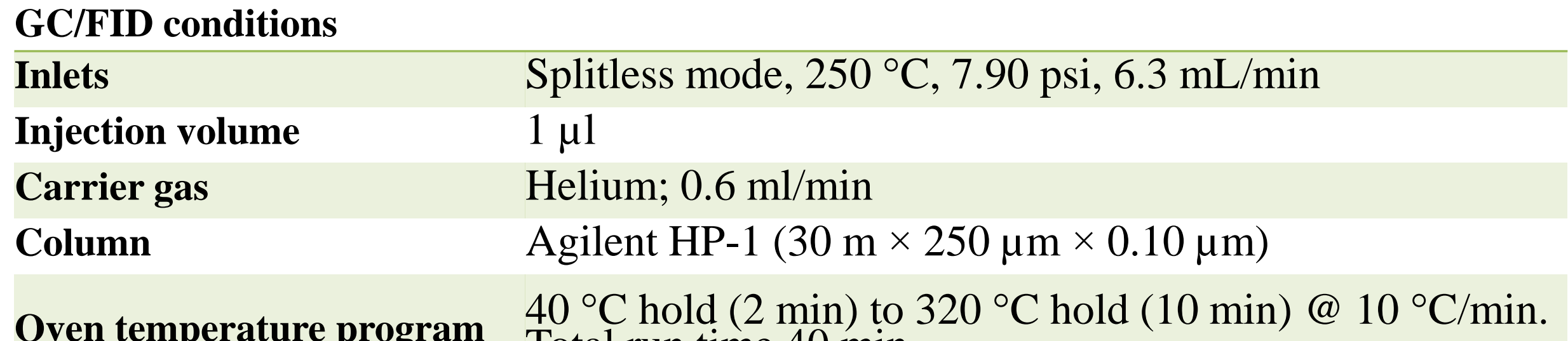

Oven temperature program $\quad 40{ }^{\circ} \mathrm{C}$ hold $(2 \mathrm{~min})$ to $320^{\circ} \mathrm{C}$ hold $(10 \mathrm{~min}) @ 10^{\circ} \mathrm{C} / \mathrm{min}$.

Table 2: GC/MS conditions used for analysis of PAHs

\begin{tabular}{ll} 
GC/MS conditions & \\
\hline Inlets & Pulsed splitless mode, $300^{\circ} \mathrm{C}, 11.747 \mathrm{psi}$ \\
Injection volume & $1 \mu \mathrm{l}$ \\
Carrier gas & Helium; $1.4 \mathrm{~m} / \mathrm{min}$ \\
Column & Restek Rxi-5SILMS $(30 \mathrm{~m} \times 250 \mu \mathrm{m} \times 0.25 \mu \mathrm{m})$ \\
\hline Oven temperature program & $50^{\circ} \mathrm{C}$ hold $(0.5 \mathrm{~min})$ to $250^{\circ} \mathrm{C} @ 25^{\circ} \mathrm{C} / \mathrm{min}$ to $290{ }^{\circ} \mathrm{C}$ hold $(3.5$ \\
\hline
\end{tabular}

\section{Results and Discussion}

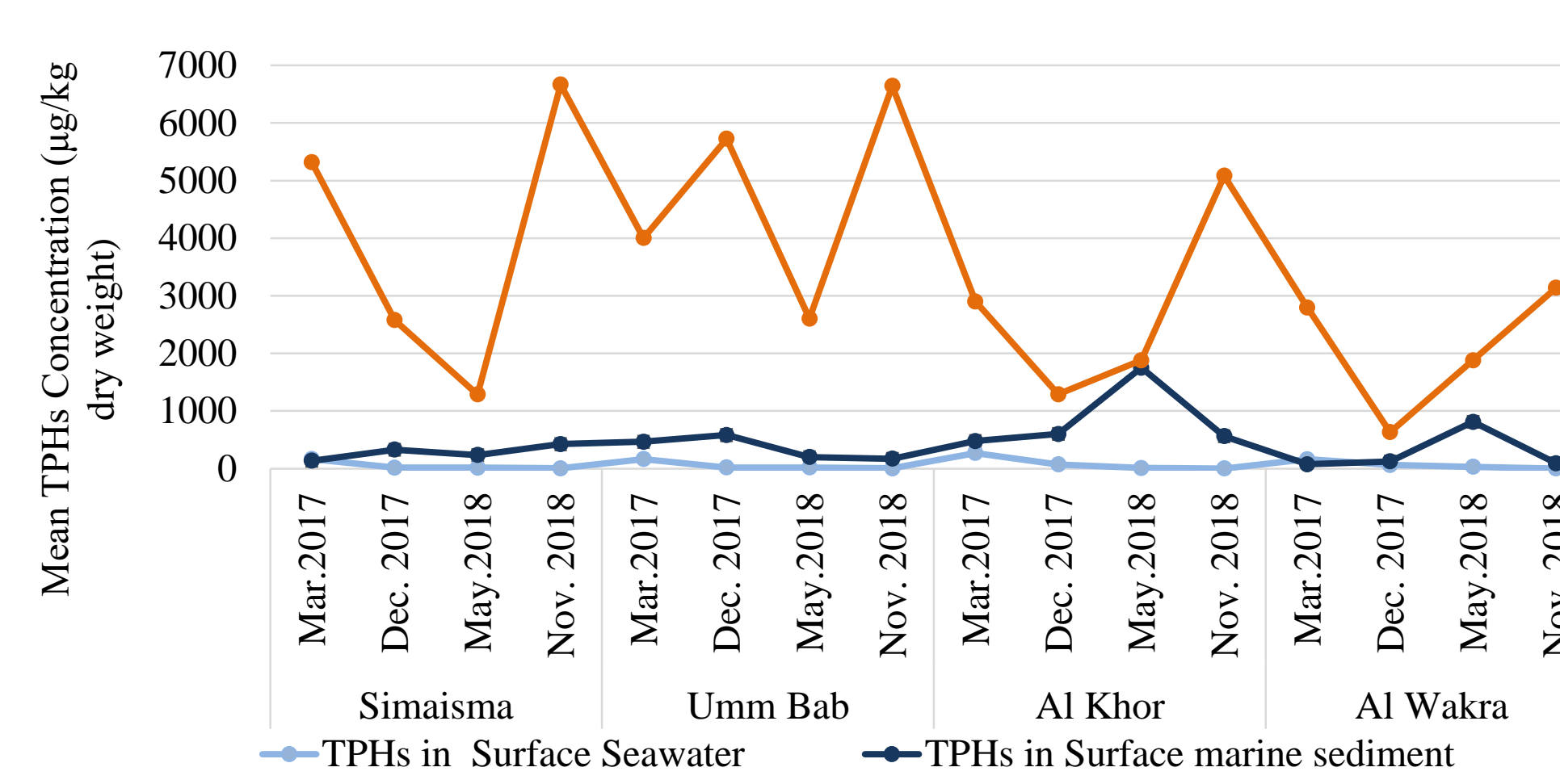

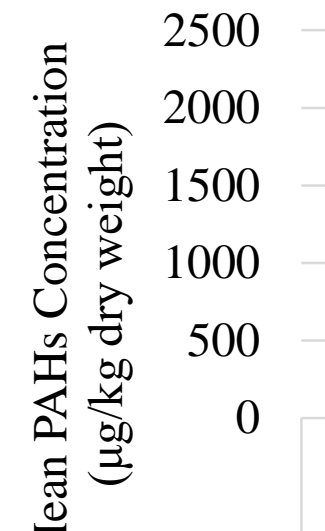

Overall, the organic contaminants (TPHs and PAHs) were more readily detected in oyster tissues samples than marine sediment and seawater samples collected from the same areas.

- Compared with previous local studies in marine sediment from Qatar, the concentrations of total PAHs ranged from (4.25 $36.73 \mu \mathrm{g} / \mathrm{kg})$ and TPHs $(75.02-1751.82 \mu \mathrm{g} / \mathrm{Kg})$ were in the range of previous local studies.

- Levels of PAHs observed in oyster tissues (25.90- 2244.03 $\mathrm{\mu g} / \mathrm{Kg}$ ) were higher than the previous local study observed by Leitão et al. (2017) who reported (0.15-23.13 $\mu \mathrm{g} / \mathrm{Kg})$.

- On the other hand, the TPHs concentration range reported in oyster tissues $(633.3-6666.7 \mu \mathrm{g} / \mathrm{Kg})$ was in the range of previous study (10 to $7410 \mu \mathrm{g} / \mathrm{Kg}$ ).$$
2000
$$

1500.00
1000.00

$$
10000000
$$$$
\text { Benzo (a) pyrene }
$$

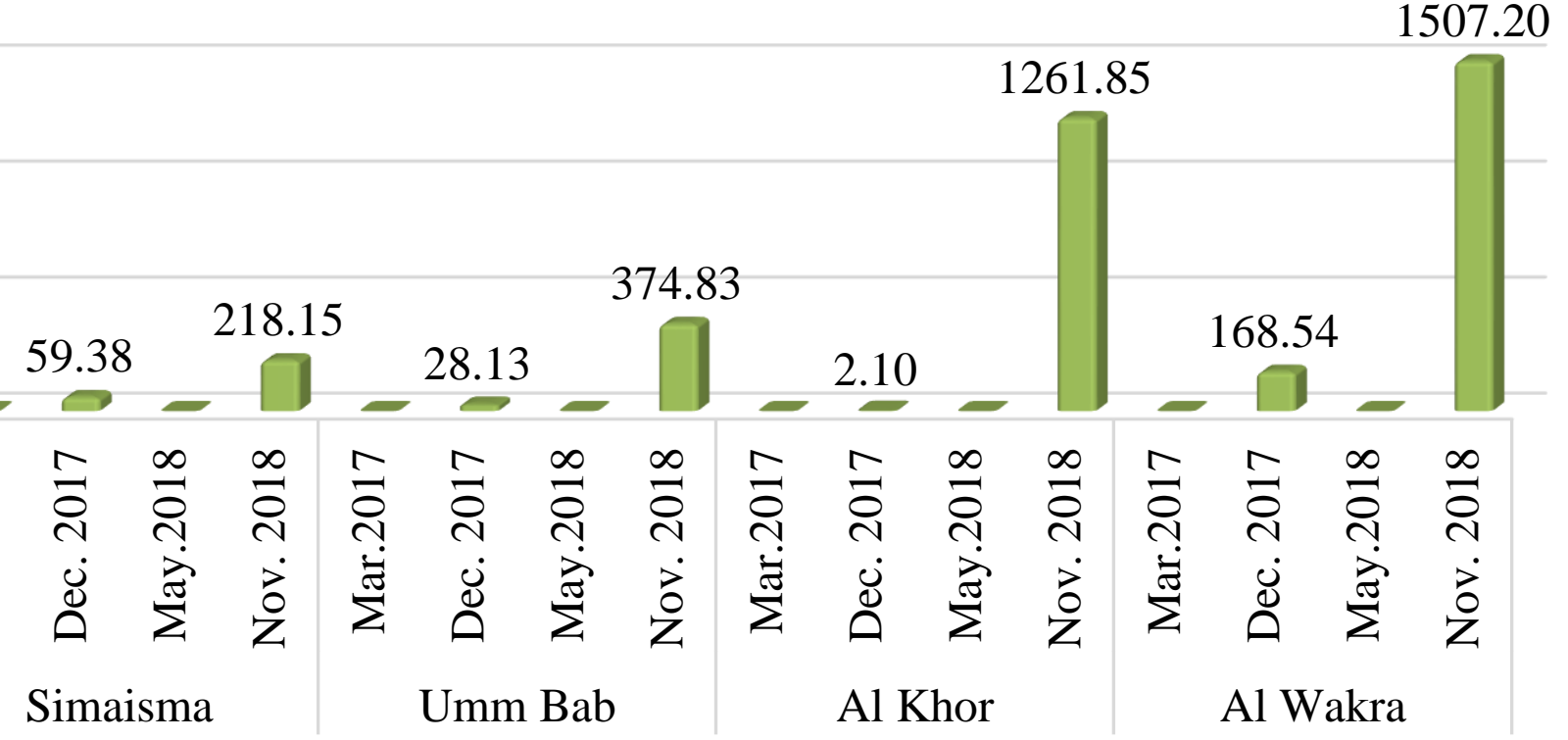

$$
\begin{aligned}
& \text { (a) pyrene } \\
& \text { weight) }
\end{aligned}
$$

The highest level of PAHs compounds found in oyster tissues was Benzo (a) pyrene which was detected only in sample collected in winter seasons (winter 2017 and winter 2018).

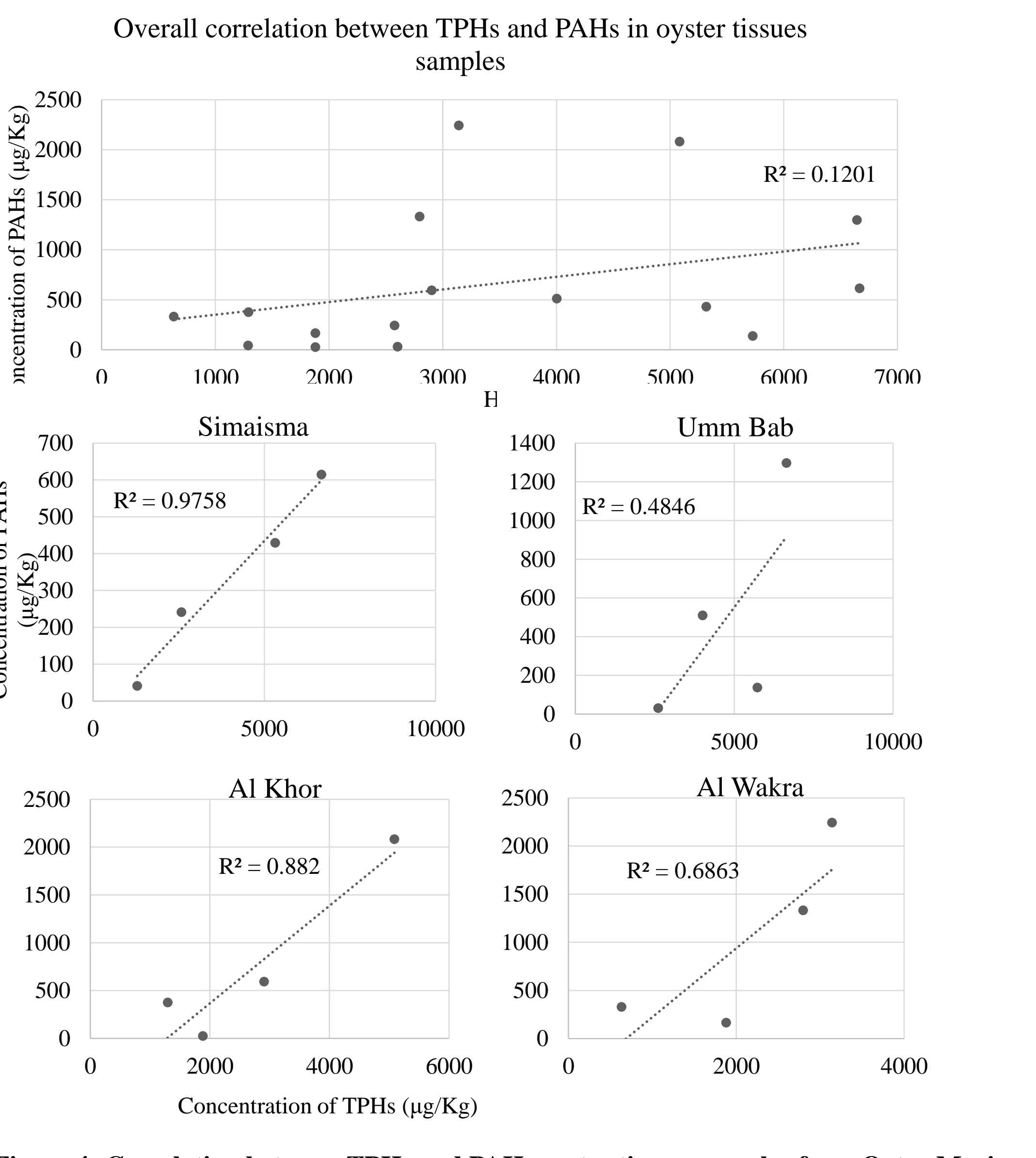

Overall, TPHs and PAHs concentrations in oyster tissues shows a week, positive, linear association with a few potential outliers. However, Simaisma shows a strong, positive, linear correlation between the both organic contaminants. Moreover, Umm Bab, Al Khor and Al Wakra shows individually a strong positive, linear correlation with a few potential outliers.

\section{Conclusion}

- The organic contaminants (TPHs and PAHs) were more detected in oyster tissues samples than marine sediment and seawater.

- Levels of PAHs in oyster tissues were higher than levels found in previous local study.

- Benzo (a) pyrene was the highest PAHs detected found in oyster tissues samples. 